\title{
A study of clinical profile and outcome of intra ventricular hemorrhage in neonates admitted to neonatal intensive care unit of a tertiary care hospital, Eluru, Andhra Pradesh, India
}

\section{Majeti Srinivasa Rao, Manas Ranjan Sahoo*, Arigela Vasundhara, Swetha K., Sudarsini P.}

Department of Pediatrics, ASRAM, Eluru, Andhra Pradesh, India

Received: 19 December 2015

Revised: 23 February 2016

Accepted: 02 March 2016

\section{*Correspondence:}

Dr. Manas Ranjan Sahoo,

E-mail:drmrsahoo@gmail.com

Copyright: (C) the author(s), publisher and licensee Medip Academy. This is an open-access article distributed under the terms of the Creative Commons Attribution Non-Commercial License, which permits unrestricted non-commercial use, distribution, and reproduction in any medium, provided the original work is properly cited.

\section{ABSTRACT}

Background: The human hemostatic system is dynamic and is profoundly influenced by age. Although considered immature in the new-born, it is a physiological system which results in few problems for the healthy term neonate, but may contribute to morbidity in the sick and preterm infants when additional acquired abnormalities may be present. The objectives were, the study has been conducted to evaluate the clinical presentation, etiological risk factors of Intraventricular haemorrhage (IVH) and to correlate the birth weight, gestational age, sex, mode of delivery, perinatal factors with the incidence of IVH and to study the immediate outcome.

Methods: This is a prospective study which included neonates admitted in the Neonatal intensive care unit (NICU) of Department of Paediatrics, Alluri Sita Rama Raju Medical College, Eluru, Andhra Pradesh, India during the period of March 2013 and September 2014. We enrolled 135 newborns in the study and blood investigations and transcranial USG was done in all.

Results: Incidence of IVH in new-borns admitted in NICU at Alluri Sita Rama Raju Medical College was $13.3 \%$ (18 out of 135 babies), whereas incidence of IVH in preterm babies was 26.9\% (17 out of 63 babies) and incidence of IVH in term babies was $1.3 \%$ ( 1 out of 72 babies). $94.4 \%$ of the new-borns with IVH had prolonged prothrombin time $(\mathrm{p}<0.01)$. Thrombocytopenia was responsible in $83.4 \%$ as an associated risk factor in the development of IVH $(\mathrm{p}<0.01)$.

Conclusions: Intraventricular Hemorrhage constitutes an important cause of morbidity and mortality in neonate. Need for assisted ventilation irrespective of the co morbidities, presence of metabolic acidosis, have been associated with increased incidence of IVH. Deranged coagulation profile (Thrombocytopenia, prolonged prothrombin time (PT)) have been associated with increased risk for the incidence of IVH in new-borns.

Keywords: IVH, PT, Activated partial thromboplastin time (APTT)

\section{INTRODUCTION}

The haemostatic system is dynamic throughout the childhood. ${ }^{1}$ The haemostatic system in the neonate has many unique features when compared with older children. ${ }^{2}$ Although considered immature in the newborn, it is a physiological system which results in few problems for the healthy term neonate, but may contribute to morbidity in the sick and preterm infants when additional acquired abnormalities may be present.

Hemorrhage both localized and generalized is a significant cause of morbidity and mortality in the neonatal period. Significant haemorrhagic complication accounts to about $1-2 \%$ of all NICU admissions and accounts to $40 \%$ of deaths associated with hemorrhage. 
The identification of the cause of bleeding is of paramount importance for the appropriate management and for prognostication.

Intraventricular hemorrhage (IVH) is a leading cause of morbidity and mortality in the new-borns most common in the preterm neonates. The paucity of Indian studies on Intraventricular hemorrhage in new-borns prompted us to do this study looking at the incidence, etiological risk factors, clinical features and the immediate outcome among the new-borns.

The aim and objectives of the study was to evaluate the clinical presentation, etiological risk factors of IVH by history, physical examination and available relevant lab investigations, to correlate the birth weight, gestational age, sex, mode of delivery, perinatal factors with the incidence of IVH and to study the immediate outcome.

\section{METHODS}

This is a prospective study which included neonates admitted in the Neonatal intensive care unit (NICU) of Department of Paediatrics, Alluri Sita Rama Raju Medical College, Eluru, Andhra Pradesh, India during the period of March 2013 and September 2014.

\section{Sample size}

135 neonates irrespective of their co morbidities, admitted in NICU at Department of Paediatrics, Alluri Sita Rama Raju Medical College, Eluru, Andhra Pradesh, India were included in the study.

Out of 391 total admissions during the specified time period, 135 new-borns were screened using relevant history, available laboratory methods and Cranial Ultrasound Examination for the evidence of IVH. Incidence, Risk factors and Immediate outcome i.e., survival or death among the neonates with Intraventricular hemorrhage were analysed using ChiSquare test and the level of significance by P-value $<0.05$.

\section{Inclusion criteria}

All the Neonates admitted in the Neonatal Intensive Care Unit at Department of Paediatrics, Alluri Sita Rama Raju Medical College, Eluru, Andhra Pradesh, India irrespective of the co morbidities were included in the study.

\section{Exclusion criteria}

Neonates who died within the first 48 hours of life, those with lack of Cranial Ultrasound examination within the first 10 days of life, and those without parent consent for screening Cranial Ultrasound Examination were excluded from the present study.

\section{Methods}

All the neonates admitted in NICU during the study period were included in the present study done at ASRAM Medical College, Eluru.

- A detailed antenatal and birth history were obtained initially from all the neonates.

The following clinical investigative procedures were performed for all the neonates

- Complete blood count.

- Leishman stained blood smear was examined in detail to look for evidence of thrombocytopenia, DIC (fragmented RBCs) and septicemia (toxic granules, shift to left, band forms of granulocytes).

- Prothrombin time (PT) and Activated partial thromboplastin time (APTT).

- Cranial Ultrasound examination/neurosonogram.

\section{Immediate outcome}

It was noted whether the child survived or expired.

\section{Statistical analysis}

Descriptive data are presented as number and percentages. Chi-square test was used to assess the association between IVH with various factors.

Microsoft word and SPSS software were used for the analysis of the results. A p value of 0.05 or less was considered for statistical significance

\section{RESULTS}

Table 1: Incidence of IVH - Sex wise distribution of study population.

\begin{tabular}{|lll|l|}
\hline Sex & IVH $(+)(\%)$ & IVH $(-)(\%)$ & Total (\%) \\
\hline Male & $14(19.72)$ & $57(80.28)$ & $71(100)$ \\
\hline Female & $4(6.25)$ & $60(93.75)$ & $64(100)$ \\
\hline Total & 18 & 117 & 135 \\
\hline
\end{tabular}

Chi Square value is 5.28 and $\mathrm{P}$-value is 0.02 .

Table 2: Sex wise distribution among IVH patients.

\begin{tabular}{|ll|}
\hline Sex & IVH + \\
\hline Male & $14(77.8 \%)$ \\
\hline Female & $4(22.2 \%)$ \\
\hline
\end{tabular}

Out of 18 babies with IVH during the study period, Incidence of IVH is more in male babies $(77.8 \%)$ compared to female babies $(22.2 \%)$ with $\mathrm{P}$ value of 0.02 at $5 \%$ level of significance. 
Table 3: Incidence of IVH: gestational age wise distribution in newborns.

\begin{tabular}{|llll|}
$\begin{array}{llll}\text { Gestational } \\
\text { age }\end{array}$ & $\begin{array}{l}\text { IVH }(+) \\
(\%)\end{array}$ & $\begin{array}{l}\text { IVH }(-) \\
(\%)\end{array}$ & $\begin{array}{l}\text { Total } \\
(\%)\end{array}$ \\
\hline Term & $1(1.3)$ & $71(98.7)$ & $72(100)$ \\
\hline Preterm & $17(27)$ & $46(73)$ & $63(100)$ \\
\hline Total & $18(13.4)$ & $117(86.6)$ & $135(100)$ \\
\hline
\end{tabular}

The incidence of IVH is found to be significantly high in preterm babies (27\%) compared to term babies $(1.3 \%)$ in the total study population.

Table 4: Gestational age wise distribution in IVH patients.

\begin{tabular}{|ll|}
\hline Gestational age & IVH + \\
\hline Term & $1(5.6 \%)$ \\
\hline Preterm & $17(94.4 \%)$ \\
\hline Total & $18(100 \%)$ \\
\hline
\end{tabular}

17 babies $(94.4 \%)$ were preterm births with Gestational age $<37$ weeks.

- 1 baby (5.6\%) was term birth with Gestational age $>37$ weeks.

- Among 63 Preterm births, incidence of IVH is $27 \%$ with 17 babies with IVH:

$\checkmark \quad 1$ baby $(5.8 \%)$ belong to $<28$ weeks Gestational age.

$\checkmark \quad 12$ babies $(70.5 \%)$ belong to $29-31+6$ week's Gestational age.

$\checkmark 4$ babies $(23.5 \%)$ belong to $>32$ weeks Gestational age.

Table 5: Incidence of IVH: birth weight wise distribution in newborns in study population.

\begin{tabular}{|llll|}
\hline $\begin{array}{l}\text { Birth } \\
\text { weight }\end{array}$ & $\begin{array}{l}\text { IVH }(+) \\
(\%)\end{array}$ & $\begin{array}{l}\text { IVH }(-) \\
(\%)\end{array}$ & Total $(\%)$ \\
\hline$<1 \mathrm{Kg}$ & $5(100)$ & $0(0)$ & $5(100)$ \\
\hline $1-1.5 \mathrm{Kg}$ & $8(61.5)$ & $5(38.4)$ & $13(100)$ \\
\hline$>1.5 \mathrm{Kg}$ & $5(4.2)$ & $112(95.7)$ & $117(100)$ \\
\hline Total & 18 & 117 & 135 \\
\hline
\end{tabular}

Chi Square value is 67; $\mathrm{P}$ - value is 0.00 for 2 d.f at $5 \%$ level of significance.

Table 6: Birth weight wise distribution in newborns with IVH.

\begin{tabular}{|ll|}
\hline Birth weight & IVH + \\
\hline$<1 \mathrm{~kg}$ & $5(27.8 \%)$ \\
\hline $1-1.5 \mathrm{~kg}$ & $8(44.4 \%)$ \\
\hline$>1.5 \mathrm{~kg}$ & $5(27.8 \%)$ \\
\hline Total & $18(100 \%)$ \\
\hline
\end{tabular}

Out of 135 babies:

- All 5 babies $(27.8 \%)$ born with birth weight $<1 \mathrm{~kg}$ developed IVH.

- 8 babies (44.4\%) out of 13 babies born with birth weight from $1-1.5 \mathrm{~kg}$ developed IVH.

- 5 babies $(27.8 \%)$ out of 117 babies born with birth weight $>1.5 \mathrm{~kg}$ developed IVH.

Table 7: Incidence of IVH: antenatal risk factor wise distribution in newborns.

\begin{tabular}{|llll|}
\hline $\begin{array}{l}\text { Antenatal } \\
\text { risk factor }\end{array}$ & $\mathrm{IVH}+(\%)$ & $\mathrm{IVH}-(\%)$ & $\begin{array}{l}\text { Total no of } \\
\text { cases }(\%)\end{array}$ \\
\hline Yes & $15(31.25)$ & $33(68.75)$ & $48(100)$ \\
\hline No & $3(3.4)$ & $84(96.5)$ & $87(100)$ \\
\hline & 18 & 117 & 135 \\
\hline
\end{tabular}

Chi Square value is 20.7 and P-value is 0.000 for 1 d.f at $5 \%$ level of significance.

Table 8: Antenatal risk factor wise distribution in newborns with IVH.

\begin{tabular}{|ll|}
\hline Antenatal risk factors & IVH (\%) \\
\hline Yes & $15(83.3 \%)$ \\
\hline No & $3(16.7 \%)$ \\
\hline Total & $18(100 \%)$ \\
\hline
\end{tabular}

Out of 18 babies with IVH during the study period, Incidence of IVH in new-borns with Antenatal risk factors was $83.3 \%$ and Incidence in new-borns without Antenatal risk factors was $16.7 \%$.

Table 9: Incidence of IVH: use of antenatal steroids in newborns.

\begin{tabular}{|lll|l|}
\hline $\begin{array}{l}\text { Antenatal } \\
\text { steroids }\end{array}$ & $\begin{array}{l}\text { IVH }(+) \\
(\%)\end{array}$ & $\begin{array}{l}\text { IVH }(-) \\
(\%)\end{array}$ & Total $(\%)$ \\
\hline Yes & $4(57.2)$ & $3(42.8)$ & $7(100)$ \\
\hline No & $14(11)$ & $114(89)$ & $128(100)$ \\
\hline Total & 18 & 117 & 135 \\
\hline
\end{tabular}

Chi Square value is 12.3 and P-value is 0.000 for $1 \mathrm{~d} . \mathrm{f}$ at $5 \%$ level of significance.

Table 10: Use of antenatal steroids in newborns with IVH.

\begin{tabular}{|ll|}
\hline Antenatal steroids & IVH + \\
\hline Yes & $4(22.2 \%)$ \\
\hline No & $14(77.8 \%)$ \\
\hline Total & $18(100 \%)$ \\
\hline
\end{tabular}

Out of 18 babies with IVH during the study period:

- Incidence of IVH in infants born to mothers with history of intake of antenatal steroids is $22.2 \%$.

- Incidence of IVH in infants born to mothers without intake of antenatal steroids is $77.8 \%$. 
Table 11: Mode of delivery and incidence of IVH in newborns.

\begin{tabular}{|llll|}
\hline MOD & IVH (+) (\%) & IVH $(-)(\%)$ & Total $(\%)$ \\
\hline Nvd & $9(11)$ & $73(89)$ & $82(100)$ \\
\hline EM.LSCS & $9(30)$ & $21(70)$ & $30(100)$ \\
\hline EL.LSCS & $0(0)$ & $23(100)$ & $23(100)$ \\
\hline Total & 18 & 117 & 135 \\
\hline
\end{tabular}

Chi Square value is 11.1 and P-value is 0.004 for 2 d.f at $5 \%$ level of significance.

Out of 18 babies with IVH during the study period, Incidence of IVH in new-borns born out of NVD was $50 \%$ and incidence in new-borns born out of Em.LSCS was $50 \%$.

Table 12: Birth asphyxia and incidence of IVH in newborns.

\begin{tabular}{|llll|}
$\begin{array}{l}\text { Birth } \\
\text { asphyxia }\end{array}$ & IVH (+) (\%) & IVH (-) (\%) & Total $(\%)$ \\
\hline $\mathrm{Y}$ & $2(8)$ & $23(92)$ & $25(100)$ \\
\hline $\mathrm{N}$ & $16(14.6)$ & $94(85.4)$ & $110(100)$ \\
\hline Total & 18 & 117 & 135 \\
\hline
\end{tabular}

Chi Square value is 0.755 and $\mathrm{P}$-value is 0.385 for $1 \mathrm{~d} . \mathrm{f}$ at $5 \%$ level of significance.

Table 13: Incidence of IVH in babies with asphyxia.

\begin{tabular}{|ll|}
\hline Birth asphyxia & IVH + \\
\hline Yes & $2(11.1 \%)$ \\
\hline No & $16(88.9 \%)$ \\
\hline Total & $18(100 \%)$ \\
\hline
\end{tabular}

Out of 18 babies with IVH during the study period:

- Incidence of IVH in new-borns born with history of birth asphyxia is $11.2 \%$.

- Incidence of IVH in new-borns born without history of birth asphyxia is $88.8 \%$.

Table 14: Incidence of IVH: general condition of study population.

\begin{tabular}{|ll|}
\hline Sensorium & IVH \\
\hline Normal & $11.1 \%$ \\
\hline Lethargic & $16.6 \%$ \\
\hline Comatose & $72.3 \%$ \\
\hline
\end{tabular}

Table 15: Assisted ventilation as a risk factor for IVH in newborns.

\begin{tabular}{|llll|}
\hline $\begin{array}{l}\text { Assisted } \\
\text { ventilation }\end{array}$ & IVH (+) (\%) & IVH (-) $(\%)$ & $\begin{array}{l}\text { Total } \\
(\%)\end{array}$ \\
\hline YES & $14(63.6)$ & $8(36.6)$ & $22(100)$ \\
\hline NO & $4(3.6)$ & $109(96.4)$ & $113(100)$ \\
\hline TOTAL & 18 & 117 & 135 \\
\hline
\end{tabular}

Chi Square value is 57.6 and P-value is 0.0000 for 1 d.f at $5 \%$ level of significance.
Out of 18 babies with IVH:

- $11.1 \%$ babies had good general condition.

- $16.6 \%$ babies were lethargic.

- $72.3 \%$ babies were comatose.

Table 16: Incidence of IVH in ventilated babies.

\begin{tabular}{|ll|}
\hline Assisted ventilation & IVH \\
\hline Yes & $14(77.7 \%)$ \\
\hline No & $4(22.3 \%)$ \\
\hline Total & $18(100 \%)$ \\
\hline
\end{tabular}

\section{Observations}

- Out of 135 babies screened for IVH, 18 babies were proven to have IVH by cranial USG examination.

- Out of 135 babies:

$\checkmark \quad 14$ babies (63.6\%) who were ventilated during the period of NICU stay developed IVH.

$\checkmark \quad 4$ babies $(3.6 \%)$ without history of invasive ventilation developed IVH.

- Out of 18 babies with IVH during the study period:

$\checkmark$ Incidence of IVH in new-borns who were ventilated during NICU stay is $77.7 \%$.

$\checkmark$ Incidence of IVH in new-borns without history of invasive ventilation during NICU stay is $22.3 \%$.

Table 17: Metabolic acidosis as a risk factor for IVH in newborns.

\begin{tabular}{|llll|}
$\begin{array}{l}\text { Metabolic } \\
\text { acidosis }\end{array}$ & $\begin{array}{l}\text { IVH }(+) \\
(\%)\end{array}$ & $\begin{array}{l}\text { IVH }(-) \\
(\%)\end{array}$ & $\begin{array}{l}\text { Total } \\
(\%)\end{array}$ \\
\hline $\mathrm{Y}$ & $5(83.3)$ & $1(16.7)$ & $6(100)$ \\
\hline $\mathrm{N}$ & $13(10)$ & $116(90)$ & $129(100)$ \\
\hline Total & 18 & 117 & 135 \\
\hline
\end{tabular}

Chi Square value is 26.6 and $\mathrm{P}$ value is 0.000 for $1 \mathrm{~d} . \mathrm{f}$ at $5 \%$ level of significance.

\section{Observations}

- Out of 135 babies screened for IVH, 18 babies were proven to have IVH by cranial USG examination.

- Out of 135 babies:

$\checkmark \quad 5$ babies $(83.3 \%)$ out of 6 babies with metabolic acidosis during the course of illness developed IVH.

$\checkmark 13$ babies (10\%) out of 129 babies without metabolic acidosis developed IVH.

Table 18: Thrombocytopenia as a risk factor for IVH in newborns.

\begin{tabular}{|llll|} 
Platelet count & $\begin{array}{l}\text { IVH }(+) \\
(\%)\end{array}$ & $\begin{array}{l}\text { IVH (-) } \\
(\%)\end{array}$ & Total $(\%)$ \\
\hline Normal & $3(3)$ & $108(97)$ & $111(100)$ \\
\hline Decreased & $15(62.5)$ & $9(37.5)$ & $24(100)$ \\
\hline Total & 18 & 117 & 135 \\
\hline
\end{tabular}

Chi Square value is 61.1 and P-value is 0.000 for $1 \mathrm{~d} . \mathrm{f}$ at $5 \%$ level of significance. 
Table 19: Incidence of thrombocytopenia in IVH newborns.

\begin{tabular}{|ll|}
\hline Thrombocytopenia & IVH \\
\hline Yes & $15(83.4 \%)$ \\
\hline No & $3(16.6 \%)$ \\
\hline Total & $18(100 \%)$ \\
\hline
\end{tabular}

\section{Observations}

- Out of 135 babies screened for IVH, 18 babies were proven to have IVH by cranial USG examination.

- 3 babies (3\%) out of 111 babies screened had normal platelet count with IVH.

- 15 babies $(62.5 \%)$ out of 24 babies screened had decreased platelet count (Thrombocytopenia) as a risk factor to develop IVH.

Out of 18 babies with IVH during the study period:

- Incidence of IVH in new-borns with Thrombocytopenia during the course of illness is $16.6 \%$.

- Incidence of IVH in new-borns without Thrombocytopenia is $83.4 \%$.

Table 20: Coagulopathy (Prothrombin time) as a risk factor for IVH in newborns.

\begin{tabular}{|llll|}
\hline PT & IVH $+(\%)$ & IVH $-(\%)$ & Total $(\%)$ \\
\hline N & $1(0.9)$ & $114(99.1)$ & $115(100)$ \\
\hline P & $17(85)$ & $3(15)$ & $20(100)$ \\
\hline Total & 18 & 117 & 135 \\
\hline
\end{tabular}

Chi Square value is 107.00 and P-value is 0.000 for $1 \mathrm{~d} . \mathrm{f}$ at $5 \%$ level of significance.

\section{Observations}

- Out of 18 babies with IVH during the study period, Incidence of IVH in new-borns with deranged or prolonged prothrombin time as a risk factor is $94.4 \%$.

- Out of 135 babies screened for IVH, 18 babies were proven to have IVH by cranial USG examination

$\checkmark \quad 1$ baby $(0.9 \%)$ had normal prothrombin time.

$\checkmark \quad 17$ babies (85\%) had prolonged prothrombin time $(\uparrow)$.

- P-Value is 0.000 at $5 \%$ Level of Significance.

Table 21: Clinical presentation of IVH in newborns.

\begin{tabular}{|ll|}
\hline Clinical presentation & IVH $(\%)$ \\
\hline Catastrophic & $3(16.6)$ \\
\hline Saltatory & $4(22.2)$ \\
\hline Asymptomatic & $11(61.2)$ \\
\hline Total & $18(100)$ \\
\hline
\end{tabular}

\section{Observations}

- Out of 135 babies screened for IVH, 18 babies were proven to have IVH by cranial USG examination.

- Out of 18 babies:

$\checkmark \quad 3$ babies (16.6\%) had catastrophic clinical presentation of IVH.

$\checkmark 4$ babies $(22.2 \%)$ had Saltatory clinical presentation of IVH.

$\checkmark 11$ babies (61.2\%) had asymptomatic clinical presentation of IVH.

Table 22: Incidence and immediate outcome of IVH in newborns of study population.

\begin{tabular}{|ll|}
\hline Outcome & IVH $(\%)$ \\
\hline Good & $13(72.2)$ \\
\hline Death & $5(27.8)$ \\
\hline Total & $18(100)$ \\
\hline
\end{tabular}

\section{Observations}

- Out of 135 babies screened for IVH, 18 babies were proven to have IVH by cranial USG examination.

- Out of 18 babies with IVH:

$\checkmark \quad 13$ babies (72.2\%) had good outcome.

$\checkmark 5$ babies $(27.8 \%)$ died during the course of illness.

\section{Incidence of IVH}

- Incidence of IVH in new-borns admitted in NICU at Alluri Sita Rama Raju Medical College, Eluru, Andhra Pradesh, India: $13.3 \%$ (18 out of 135 babies).

- Incidence of IVH in preterm babies: $26.9 \%$ (17 out of 63 babies).

- Incidence of IVH in term babies: $1.3 \%$ (1 out of 72 babies).

\section{DISCUSSION}

In the present study out of the 391 neonates admitted in NICU in $1 \frac{1}{2}$ years, 135 neonates were included in the study in regards to the inclusion criterion and 18 newborns out of 135 had IVH irrespective of co morbidity. The overall incidence of IVH in the present study is $13.3 \%$, majority being Preterm neonates with an incidence of $26.9 \%$ and in Term neonates it was $1.3 \%$.

Out of 18 new-borns with IVH, $77.8 \%$ were males and $22.2 \%$ were females with a Male: Female ratio of 3.5:1. In the present study, out of 135 babies screened for IVH, 63 babies were preterm babies with gestational age less than 37 weeks. Out of 63 preterm babies admitted in NICU, 17 babies were detected to have IVH by cranial ultrasound examination. Of 17 babies with IVH, incidence of IVH was more in preterm born between 29$31+6$ weeks gestational age $(70.5 \%)$ compared to those born $>32$ weeks gestational age $(23.5 \%)$ and $<28+6$ weeks gestational age $(5.8 \%)$. 
This is similar to the study done by Volpe et al. in 2001, with incidence of IVH more in preterm babies when compared to term neonates, indicating that IVH is a leading cause of brain injury in preterm new-born babies. ${ }^{3}$

In the present study, out of 18 babies with IVH, incidence of IVH in infants with birth weight $<1 \mathrm{~kg}$ was $27.8 \%$, birth weight between $1 \mathrm{~kg}-1.5 \mathrm{~kg}$ was $44.4 \%$ and birth weight $>1.5 \mathrm{~kg}$ was $27.8 \%$. The association was statistically significant $(\mathrm{p}<0.001)$.

This is similar to the findings by a study conducted by Badiee $\mathrm{Z}$ at Iran indicating that preterm and very low birth weight infants have an increased risk for the incidence of IVH. ${ }^{4}$

The risk of IVH is inversely related to gestational age and birth weight. In addition to having several adverse effects of Preterm birth, IVH is one of the morbidities. Out of 135 babies screened, 48 babies had antenatal risk factors of which, 15 babies $(31.21 \%)$ developed IVH and 3 babies $(3.4 \%)$ without antenatal risk factors developed IVH.

Therefore, out of 18 babies with IVH during the study period, incidence of IVH was more in new-borns with antenatal risk factors $(83.3 \%)$ compared to those without any antenatal risk factors $(16.7 \%)$.

Among 135 babies screened for IVH, 4 babies (57.2\%) out of 7 babies born to mothers with history of intake of antenatal steroids developed IVH and 14 babies (11\%) out of 128 babies born to mothers without history of intake of antenatal steroids developed IVH.

Therefore out of 18 babies with IVH during the study period, incidence in infants born to mothers with history of intake of antenatal steroids was $22.2 \%$ and in those infants born to mothers without history of intake of antenatal steroids was $77.8 \%$.

Out of 135 babies, 9 babies (11\%) out of 82 babies born out of normal vaginal delivery developed IVH and 9 babies $(30 \%)$ out of 30 babies born out of emergency LSCS developed IVH.

Among 18 babies with IVH in the study period, incidence of IVH in new-borns born out of normal vaginal delivery was $50 \%$ and incidence of IVH in those born out of emergency LSCS was $50 \%$.

In the present study which was done at a tertiary hospital, there was equal incidence of IVH in new-borns born out of normal vaginal delivery as well as emergency LSCS. In a study conducted by Wells JT, Ment LR regarding the Prevention of IVH in preterm infants, it was examined whether delivery practices affect the incidence of IVH. Although often contradictory, these results suggest the possibility that active labor and vaginal delivery may be a risk factor for developing early onset IVH. ${ }^{5}$

Among these 135 babies, 2 babies (8\%) out of 25 babies with history of birth asphyxia developed IVH and 16 babies $(4.6 \%)$ out of 110 babies without history of birth asphyxia developed IVH.

However, among 18 babies with IVH in the study population, incidence of IVH in babies with history of birth asphyxia was $11.2 \%$ and incidence in those without history of birth asphyxia was $88.8 \%$.

This was however statistically not significant with pvalue 0.385 .

In another study done by Gazzolo, Diego, Di Iorio, et al on term asphyxiated new-borns, S100B protein blood concentrations were determined at 12 hours of birth. This study suggested that elevated S100B protein blood levels represent a useful tool for the early detection of IVH in the post-asphyxia period when clinical examination and cerebral ultrasound might still be silent. ${ }^{6}$

However the most frequent causes of IVH in term neonates are birth asphyxia and birth trauma.

Among 135 babies screened, 14 babies (63.6\%) out of 22 babies who were ventilated during the period of NICU stay developed IVH and 4 babies (3.6\%) out of 113 babies without history of invasive ventilation during NICU stay developed IVH.

However, among 18 babies who developed IVH in the study population, incidence in babies with history of mechanical ventilation during the period of NICU stay was $77.7 \%$ and in those without history of mechanical ventilation was $22.3 \%$. In a study conducted by Aly $\mathrm{H}$, Hammad TA, Essers J, Wung JT at an American hospital, data was collected on delivery room intubation and mechanical ventilation during the first 3 days of life in very low birth weight infants. ${ }^{7}$

Among 135 babies screened, 5 babies $(83.3 \%)$ out of 6 babies with metabolic acidosis during the course of illness developed IVH and 13 babies (10\%) out of 129 babies without metabolic acidosis developed IVH in the study population.

However, among 18 babies with IVH in the study population, incidence of IVH in new-borns with metabolic acidosis as a risk factor during the course of illness was $27.7 \%$ and incidence among those without metabolic acidosis was $72.3 \%$.

This was proven to be statistically significant in our study with p-value 0.000 .

Dykes et al found that administration of sodium bicarbonate after the first day of life was also a 
significant risk factor in the development of IVH. Intrapartum fetal asphyxia with metabolic acidosis, although an infrequent occurrence in the preterm infant, may account for a few cases of periventricular leucomalacia, while the more common new-born metabolic acidosis, when of sufficient degree and duration, carries a high risk of periventricular leucomalacia. ${ }^{8}$

Among 135 babies, 3 babies (3\%) out of 106 babies with normal platelet count developed IVH and 15 babies $(62.5 \%)$ out of 24 babies with decreased platelet count (Thrombocytopenia) developed IVH.

Therefore, out of 18 babies of the total study population with IVH, incidence of IVH in those born with normal platelet count was $16.6 \%$ and incidence of IVH in babies with decreased platelet count (Thrombocytopenia) is $83.4 \%$.

Another study done at an American institute included infants $<1500 \mathrm{gms}$ to investigate the significance of neonatal thrombocytopenia on the incidence of IVH in infants $<1500$ gms confirms that thrombocytopenia and IVH are not uncommon in neonates who weigh $<1500$ gms, and that the incidence of IVH is higher in those thrombocytopenic infants delivered vaginally. ${ }^{9}$

Among 135 babies, 1 baby (0.9\%) out of 115 babies with normal prothrombin time developed IVH, 17 babies ( $85 \%$ ) out of 20 babies with prolonged prothrombin time developed IVH during the course of Illness in the period of NICU stay.

However, among 18 babies with IVH, incidence of IVH in new-borns with deranged or prolonged prothrombin time as a risk factor was $94.4 \%$.

Another study was carried out by Setzer ES et al at a tertiary level hospital to investigate platelet count, bleeding time, platelet aggregation, prothrombin time, activated partial thromboplastin time, and fibrinogen level in VLBW infants during the first postnatal day to determine the relationship between hemostatic disorders and IVH. The results showed that infants with IVH had a significantly longer mean Prothrombin time than did infants with no IVH. ${ }^{10}$

Among the 18 babies with IVH in the study population, 3 babies $(16.6 \%)$ had catastrophic clinical presentation of IVH, 4 babies $(22.2 \%)$ had Saltatory clinical presentation of IVH, and 11 babies $(61.2 \%)$ were asymptomatic at the time of presentation of IVH.

It is rare to find a catastrophic presentation unless there is additional ICH, such as large SDH or parenchymal hemorrhage. ${ }^{11}$ It is a classic presentation of major hemorrhage, i.e., a neurological deterioration that usually evolved in minutes to hours and consisted of deep stupor or coma. ${ }^{12,13}$
In the present study, out of 135 babies, 18 babies were proven to have IVH by cranial ultrasound examination. Among 18 babies with IVH, 13 babies (72.2\%) had good immediate outcome with improved neurological status and 5 babies $(27.8 \%)$ died during the course of illness in the period of NICU stay at Department of Paediatrics, Alluri Sita Rama Raju Medical College, Eluru, Andhra Pradesh, India.

\section{CONCLUSION}

From current study, we concluded that:

- Intraventricular Hemorrhage constitutes an important cause of morbidity and mortality in neonate.

- Preterm and VLBW infants have higher incidence of IVH

- IVH in term babies is a rare diagnosis and can occur due to birth trauma, birth asphyxia or deranged coagulation profile.

- Antenatal risk factors and maternal antenatal steroid intake also influence the incidence of IVH in newborns.

- Need for assisted ventilation irrespective of the co morbidities, presence of metabolic acidosis, have been associated with increased incidence of IVH.

- Deranged coagulation profile (Thrombocytopenia, prolonged prothrombin time) have been associated with increased risk for the incidence of IVH in newborns.

\section{Funding: No funding sources}

Conflict of interest: None declared

Ethical approval: The study was approved by the Institutional Ethics Committee

\section{REFERENCES}

1. Forrestier F. Haematological values of 163 normalfetus between 18 and 30 weeks of gestation. Pediatr Res. 1986;20:342-6.

2. Andrew M. Development of the human coagulation system in the full term infant. Blood. 1987;70(1):165-72.

3. Volpe JJ. Intracranial hemorrhage: Germinal matrix hemorrhage. In: Volpe, JJ. Editor. Neurology of the newborn. Philadelphia: Saunders Elsevier. 2008:517-88.

4. Linder N, Haskin O, Levit O, Klinger G, Prince T, Naor N. Risk factors for IVH in VLBW premature infants: a retrospective case- control study. Pediatrics. 2003;11:e590-5.

5. James A, Low MD, Alison F. Froese MD. The association of fetal and newborn metabolic acidosis with severe periventricular leucomalacia in preterm newborn. J Obstet Gynecol. 1990;162:977-82.

6. Van de Bor M, Verloove- Vanhorick SP, Brand R, Keirse MJ, Ruys JH. Incidence and prediction of periventricular- intraventricular hemorrhage in very preterm infants. J Perinat Med. 1987;15(4):333-9. 
7. Kenny JD, Garcia-Prats JA, Hilliard JL, Corbet AJ, Rudolph AJ. Hypercarbia at birth: a possible role in the pathogenesis of IVH. Pediatrics. 1978;62(4):465-7.

8. Vieira, Renata A, Ceccon. Profile of hemodynamic changes in preterm neonates: The light in the end of tunnel. Pediatric Critical Care Medicine: 2014(15);7:688-9.

9. Bassan H, Limperopoulos C, Visconti K. Neurodevelopmental outcome in survivors of periventricular hemorrhagic infarction. Pediatrics. 2007;120(4):785-92.

10. Andrew M, Paul M. Developmental hemostasis: Relevance to Newborns andInfants. In: Nathan DG,
Orkin SH, Ginsburg D, Thomas AL, editors. Hematology of Infancy and Childhood, 6thed. Philadelphia: Saunders. 2003:121-62.

11. Soul JS. Intracranial hemorrhage. In: Cloherty TP, Eichenwald EC, Stark AR, editors. Manual of neonatal care. $7^{\text {th }}$ ed. Philadelphia: Lippincott Williams and Wilkins. 2012:686-706.

12. Aly H, Hammad TA, Essers J, Wung JT. Is mechanical ventilation associated with IVH in preterm infants? Brain dev. 2012;34(3):201-5.

13. Gazzolo, Diego, Di Iorio. S100B protein is increased in asphyxiated term infants developing IVH. Critical care medicine. 2002:30(6):1356-60.

Cite this article as: Rao MS, Sahoo MR, Arigela V, Swetha K, Sudarsini P. A study of clinical profile and outcome of intra ventricular hemorrhage in neonates admitted to NICU of a tertiary care hospital, Eluru, Andhra Pradesh, India. Int J Contemp Pediatr 2016;3:373-80. 